\title{
The Impact of Luteinizing Hormone/Chorionic Gonadotropin Hormone Receptor Gene Polymorphism rs68073206 in Men with Non-obstructive Azoospermia: A Case-control Study
}

\author{
Abdul-Rahim A. Ali ${ }^{1}$, Omar F. Abdul-Rasheed ${ }^{1 *}$ (D) Ula Al-Kawaz ${ }^{2}$ (D) \\ ${ }^{1}$ Department of Chemistry and Biochemistry, College of Medicine, Al-Nahrain University, Baghdad, Iraq; ${ }^{2}$ Department of Male \\ Infertility, High Institute of Infertility Diagnosis and Assisted Reproductive Technologies, Al- Nahrain University, Baghdad, Iraq
}

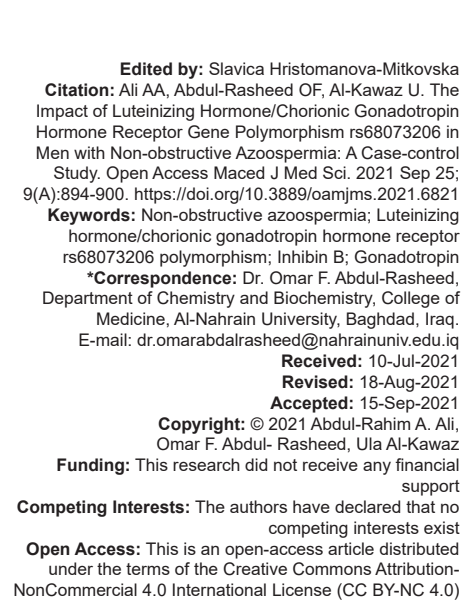

\section{Introduction}

Infertility is a global health problem that affects up to $15 \%$ of all couples trying to conceive a child. About half of all infertility conditions caused by factors attributed to the male partner [1]. The male factor infertility etiology is complicated and not yet completely established; environment, lifestyle risk factors, and genetic causes are the probable risk factors. The genetic casualties, including; chromosomal aberrations, single-gene mutations, and polymorphisms, depict appreciable roles in provoking male factor infertility among these risk factors. Genetic abnormalities may affect approximately $15 \%$ of male infertility [2].

Azoospermia can be stated as the total lack of sperms in the sediment of an ejaculate following centrifuge analysis on at least two occasions [3], [4]. This phenomenon is observed in $1.9 \%$ of the entire population and $10-15 \%$ of men presenting with infertility [4]. Non-obstructive azoospermia (NOA) is established in approximately $15 \%$ of cases of male factor infertility [5] impacts nearly $60 \%$ of azoospermia conditions and is considered as the most severe manifestation of male infertility [6]. The NOA is caused by impaired spermatogenesis, and this state of severe germ cell failure is commonly manifested as elevated follicle-stimulating hormone (FSH) concentrations with atrophied testicles [6], [7].

The luteinizing hormone/choriogonadotropin receptor (LHCGR) receptor (also named as the luteinizing hormone receptor) through ligand stimulation by $\mathrm{LH}$ or by its analog hormone/chorionic gonadotropin (HCG), will induce steroidogenesis, thereby contribute to the process of spermatogenesis. In addition to its fundamental role in both males and females, fetal gender differentiation and driving reproductiverelated physiology [8]. The extent of the stimulation process by gonadotropins, HCG, and LH, in terms of testosterone production in a murine Leydig cell model, was comparable [9], [10].

The LHCGR belongs to the G-protein-coupled receptors (GPCRs) class A [11]. The LHCGR gene 
localized at chromosome 2p21 has consisted of 12 exons. The LHCGR extracellular domains responsible for ligand binding are encoded by Exons 1 to 10 in addition to part of exon 11. The left portion of exon 11 of the LHCGR gene is encoding for each transmembrane receptor domain consisting of seven consecutive helices and the intracellularly located C-terminal domains, specialized in transducing signaling cascades [12].

Multiple polymorphic variants were exhibited and detected in the LHCGR gene [11], [13]. Nevertheless, various polymorphisms in LHCGR were silent and unlikely to have functional significance [14]. Another study of 278 patients with maldescended testes estimated the association linking LHCGR genetic polymorphisms and the disease, and it was concluded that rs2293275 single nucleotide polymorphism (SNP) (Ser312Asn) within the LHCGR gene exon 10 was pronounced, spermatogenetic damage associated resulting in a state of NOA, as prevailed by its significant predominance amongst infertile men, whether compared to that with maldescended testicles [15]. Furthermore, it was conferred that; even though these findings of LHCGR polymorphisms by themselves, look to impart a merely marginal influence on the described phenotypes in view of male factor infertility but, by combining with effects of other polymorphisms, these genetic variants consequences could be effective [14]. It is prevailed by the forementioned literature that; the LHCGR gene polymorphisms' consequences on both the male infertility incidence and treatment effectiveness of the condition are not clearly elucidated.

The present study was designed to examine whether the presence of LHCGR gene; (rs68073206) SNPs can be associated with the incidence of NOA in infertile Iraqi men and to assess the impact of the investigated SNP genotypic patterns on modulation of the gonadal endocrine function in azoospermic infertile men.

\section{Materials and Methods}

The current study was conducted in a case- control design from February 2019 to January 2020. The protocol was approved by the Department of Chemistry and Biochemistry Scientific Committee. Seventy patients who met the requirements of the inclusion criteria had been chosen for the current study, in addition to 34 healthy normozoospermic fertile individuals, were selected to be a study control.

Male patients were recruited from The High Institute for Infertility Diagnosis and Assisted Reproductive Technologies, Al-Nahrain University, Baghdad-Iraq, who could not get pregnant for at least 1 year with non-protected regular coitus. The patient's clinical condition and the sort of azoospermia had been got from their medical records, along with a specialized urologist checking and confirmation. First, two separately performed seminal fluid analyses in confirming azoospermia. The entire patients were subjected to an extensive clinical checkup, including the physical examination, clinical history, endocrinological, and seminal laboratory examinations. Obtained findings by these examinations pointed to this type of male infertility.

The inclusion criteria of the patient enrolment included; (1) a state of male factor infertility lasting for 1 year at minimum with a reproductively intact wife; (2) at least two consecutive spermiograms within 6 weeks affirming azoospermia according to the WHO criteria [3]; (3) 3 months' period at minimal free from receiving a potent androgen preparation.

Exclusion criteria were (1) any evidenced etiology of infertility post the thorough clinical laboratory investigations, including genetic disorders; (2) any confirmed infectious or immunological conditions or any major systemic illness; (3) any pathological hormonal estimates including dysfunctional thyroid or adrenal glands or overt hyperprolactinemia; (4) abnormal psychological stresses; and (5) major scrotal surgeries as vasectomy or any reported male reproductive ductal injury had been ruled out from the study.

The study was additionally attained approval by the Institutional Review Board of the College of Medicine at Al-Nahrain University in accordance with the Helsinki Committee for sample collection and performing the analyses (Annex) [16]. Enrolment in the study had have done after obtaining informed consent from all participants.

\section{Seminal fluid analysis}

The semen samples were obtained by masturbation preceded by an abstinence interval ranging from 2 to 7 days, near the laboratory for limiting the time separating the collection of semen and analysis process. The physical properties of each semen sample, including; the volume, $\mathrm{pH}$ value, seminal fluid color, time of liquefaction, and seminal viscosity, were investigated, then the samples were examined under the microscope to evaluate the sperms' motility levels, the vitality, concentration values, and the morphology. The collected values are then compared to the stated WHO manual's reference values [3].

\section{Genetic analysis}

The selection of candidate LHCGR gene SNPS of the NOA

The investigated SNPs in the current study were chosen relying on the ClinVar, screening OMIM, and the SNPedia. The reported SNPs described 
being with a higher susceptibility for NOA regarding the association of hypothalamic-pituitary-gonadal axis deregulating potential of these SNPs with the pathophysiology of NOA (Table 1).

\section{blood}

\section{Extraction of genomic DNA from whole}

QuicK-DNATM Miniprep Kit (Catalog NO. D3025) was utilized to perform purification and attain an extracted high-quality DNA from whole blood samples collected in EDTA anticoagulant-containing tubes characterized by simplified procedure design for the quick isolation processes of the entire genomic DNA from the whole blood. The obtained product was then optimized to achieve maximal recovery of samples with ultra-pure DNA without detectable RNA contaminations compatible with fresh or stored samples.

\section{LHCGR rs68073206 SNP detection by quantitative real-time polymerase chain reaction (PCR)}

The rs68073206 LHCGR genetic polymorphism genotyping had been conducted using the real-time PCR technique. The probe specific for the more frequent gene allele (wild allele $G$ ) was tagged with VIC reporter dye at 5' end, and the probe specific for the less frequent gene allele (mutated allele T) was marked with FAM reporter dye at 3' end. After reviewing the amplification plot curves, the results were verified, as shown in Figures 1 and 2.

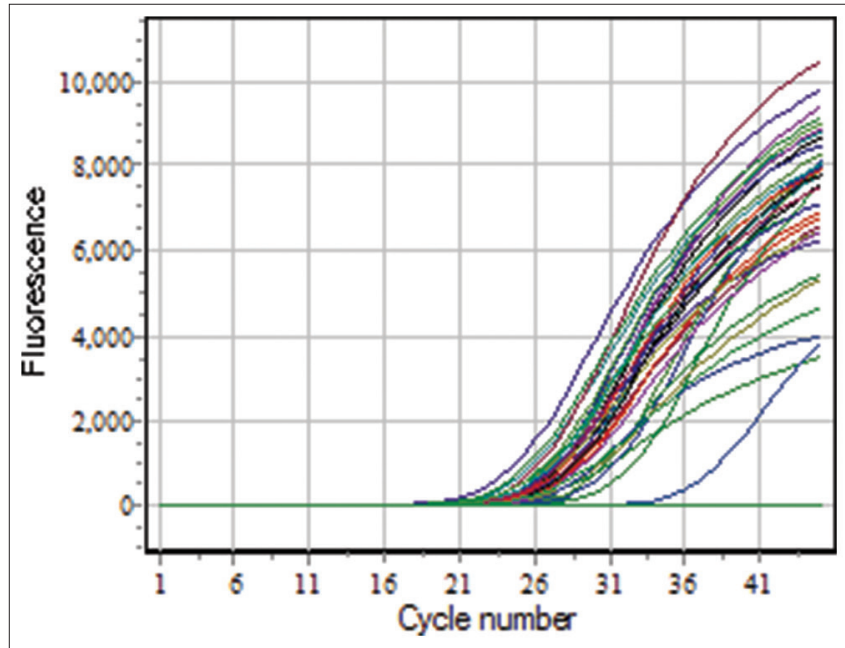

Figure 1: Amplification plot curves dependent on VIC channel fluorescence on cycle number, representing $G$ allele (rs68073206)

All subjects were categorized as being (GG) for the homozygous wild genotype of (rs68073206) LHCGR gene, (GT) for heterozygous



Figure 2: Amplification plot curves dependent on FAM channel fluorescence on cycle number, representing the T allele (rs68073206)

polymorphism, and (TT) for homozygous mutated genotype.

The sequence performed the PCR amplification steps; an initial step at $94^{\circ} \mathrm{C}$ for $5 \mathrm{~min}$; then, a consecutive 30 repeated cycles comprised of steps of DNA denaturation at the temperature of $94^{\circ} \mathrm{C}$ for $30 \mathrm{~s}$, then an annealing process at $60^{\circ} \mathrm{C}$ persisting for $30 \mathrm{~s}$, then an elongation process at a temperature of $72^{\circ} \mathrm{C}$ for $1 \mathrm{~min}$; with DNA final extension at $72^{\circ} \mathrm{C}$ for $10 \mathrm{~min}$.

\section{Hormonal assays}

After venous collection of blood samples and serum prepared, levels of the following hormones were determined: Inhibin B, FSH, luteinizing hormone (LH), estradiol (E2), progesterone, free testosterone, and prolactin. The concentrations were determined in each of the two azoospermic infertile groups and the healthy fertile group. According to the manufacturer's instructions, the concentrations were determined using the ELISA technique (kits supplied by Monobind Incorporation, USA).

\section{Statistical analysis}

All statistical analyses of the study results were carried out using SPSS (version 24) software. Linear regression was used repeatedly to compare the means of clinical parameters across genotypes (To compare the means of the genotypes, linear regression was done separately). In addition, Chi-square was used to compare the effect of genotype on the responses of treatment.

Table 1: Nomenclature of the investigated gene and polymorphisms in the present study

\begin{tabular}{|c|c|c|c|c|c|c|c|}
\hline Gene & Locus & refSNP & DNA nucleotide & $\begin{array}{l}\text { Single-nucleotide } \\
\text { variation }\end{array}$ & $\begin{array}{l}\text { NCBI nucleotide } \\
\text { reference sequence }\end{array}$ & Protein & $\begin{array}{l}\mathrm{NCBI} \text { protein } \\
\text { reference sequence }\end{array}$ \\
\hline LHCGR & 2p16.3 in Homo sapiens & rs68073206 & c. $536+1888 \mathrm{~T}>\mathrm{G}$ & g. $48948707 A>C$ & NT_022184.16 & LHCGR: Intron Variant & $\mathrm{N} / \mathrm{A}$ \\
\hline
\end{tabular}




\section{Results}

Seventy infertile patients with NOA collected throughout the present study were divided into two groups according to their receiving infertility treatment (rFSH, rHCG or HMG injection) or not, comprised 33 azoospermic patients not received treatment yet (Group patient I) and 37 azoospermic patients receiving infertility treatment (Group patient II), as well as 34 fertile, healthy subjects as a control group as listed in Table 2.

Table 2: Mean \pm SEM of age, BMI, duration of infertility of different studied groups

\begin{tabular}{llll}
\hline Groups & Age (years) & BMI $\left(\mathrm{kg} / \mathrm{m}^{2}\right)$ & Duration of infertility (years) \\
\hline Patient I & $31.58 \pm 1.059$ & $26.17 \pm 0.8108$ & $5.030 \pm 0.6966$ \\
Patient II & $33.46 \pm 1.173$ & $28.70 \pm 0.919$ & $6.378 \pm 0.505$ \\
Control & $33.59 \pm 1.222$ & $26.67 \pm 0.6429$ & - \\
ANOVA P value & 0.995 & 0.175 & 0.116 \\
\hline "The difference is significant $(p \leq 0.05),{ }^{* *}$ The difference is highly significant ( $\left.p \leq 0.01\right)$, BMI: Body mass \\
index, Patient I: Azoospermic patients did not receive treatment, Patient II: Azoospermic patients were \\
receiving treatment.
\end{tabular}

\section{Anthropometric measurements and clinical characteristics of infertile patients and fertile control groups}

The mean \pm standard error of the mean (SEM) of age in years for the healthy control group was (33.59 \pm 1.222$)$ and for the untreated infertile patient group (patient I) with azoospermia was $31.58 \pm 1.059$, and for infertile patients with azoospermia (patient II) receiving treatment was $33.46 \pm 1.173$ ), respectively. No statistically significant variations $(p>0.05)$ were found between each of the study groups.

The mean \pm SEM of the body mass indexs $(\mathrm{BMI})$ in $\mathrm{kg} / \mathrm{m}^{2}$ for the healthy fertile control group (26.67 \pm 0.6429$)$ and azoospermic infertile patient group not receiving treatment (patient I) $(26.17 \pm 0.8108)$ and for those on treatment (patient II) $(28.70 \pm 0.919)$ respectively, there were no significant differences $(p>0.05)$ between them.

The mean \pm SEM of the duration of infertility in years for the azoospermic infertile patient group not receiving treatment (patient $\mathrm{I})=5.030 \pm 0.696$ and for patients group on treatment (patient II) $=6.378 \pm 0.505$ ) respectively, there were no statistically significant differences detected ( $p>0.05$ ) between the patients' groups.
Results of rs68073206 SNP genotyping of

\section{LHCGR gene}

Table 3 summarizes the allele frequencies and the genotypic distributions of different study subjects. The LHCGR SNP variant rs68073206 (located on chromosome 2) was presented with three genotypes ( $G G, G T$, and TT) and two alleles ( $G$ and $T$ ).

In all patient and the control groups, statistically non-significant differences were reported in genotyping and allele frequency among individuals carrying each of the GG, GT, or TT genotypes of the LHCGR gene (rs68073206) polymorphism (Table 3).

The homozygous wild genotype (GG) of LHCGR gene (rs68073206) was revealed to be (concerning [GT] and [TT] genotypes) as following; in infertile patients group (I) with a frequency of (52\%), in the patient group (II) (57\%), and control group (56\%), respectively. Whereas the statistical analysis revealed a non-significant variation in the distribution of the genotypes among different study groups.

To examine the statistical significance of variations in distribution frequency of the LHCGR rs68073206 G/T genotyping results, the Chi-square test was employed for the aim of investigating the odds ratios, the significance of differences of the genotypic distribution frequencies in terms of evaluating their potential risk factor for developing of azoospermia in patient groups in comparison to the healthy control group. As shown in Table 4, the genotyping variations of patients, whether carrying the homozygous GG, heterozygous GT, or homozygous TT genotype, did not reveal a statistically significant difference in distribution as compared to control individuals, so which genotype is associated with higher risk to develop the condition is did not exhibited.

Furthermore, an ANOVA test was used to stratify all of the studied serum hormonal parameters (inhibin B, LH, FSH, free testosterone E2, progesterone, and prolactin) as specified by the different genotypic variants of LHCGR gene rs68073206 SNP in numerous study groups, as revealed in Table 5.

The results revealed a statistically significant higher hormonal level of serum inhibin B in infertile patients who did not receive treatment with wild GG genotype $(246.445 \pm 224.106 \mathrm{pg} / \mathrm{ml})$, and the $\mathrm{p}$-value is (0.0439) as compared to that hormone levels of GT and

Table 3: Genotyping of rs68073206 LHCGR gene polymorphism with allele distribution frequency in the study groups

\begin{tabular}{|c|c|c|c|c|c|c|c|c|c|c|}
\hline \multicolumn{11}{|c|}{ LHCGR rs68073206 SNP genotype frequency (\%) } \\
\hline Group & & GG & GT & TT & G & $T$ & Significance & Chi-squared & $p$-value & Total \\
\hline \multirow[t]{2}{*}{ Patient I } & No. & 17.00 & 13.00 & 3.00 & 47.00 & 19.00 & NS & 0.0507 & 0.975 & 33 \\
\hline & $\%$ & 52 & 39 & 9 & 70 & 30 & & & & \\
\hline Patient II & No. & 21.00 & 12.00 & 4.00 & 54.00 & 20.00 & NS & 1.169 & 0.5573 & 37 \\
\hline \multirow[t]{2}{*}{ Control } & $\begin{array}{l}\% \\
\text { No. }\end{array}$ & $\begin{array}{l}57 \\
19.00\end{array}$ & $\begin{array}{l}32 \\
10.00\end{array}$ & $\begin{array}{l}11 \\
5.00\end{array}$ & $\begin{array}{l}73 \\
48.00\end{array}$ & 20.00 & NS & 2.892 & 0.2355 & 34 \\
\hline & $\%$ & 56 & 29 & 15 & 70 & 30 & & & & \\
\hline $\begin{array}{l}\text { Significance } \\
\text { p-value }\end{array}$ & & $\begin{array}{l}\text { NS } \\
0.8972\end{array}$ & $\begin{array}{l}\text { NS } \\
0.6751\end{array}$ & $\begin{array}{l}\text { NS } \\
0.7607\end{array}$ & $\begin{array}{l}\text { NS } \\
0.9476\end{array}$ & $\begin{array}{l}\text { NS } \\
0.9476\end{array}$ & & & & \\
\hline Total & & 57 & 35 & 12 & 149 & 59 & & & & \\
\hline
\end{tabular}


TT genotypes carriers that were $(85.969 \pm 71.685 \mathrm{pg} / \mathrm{ml})$ and $(56.420 \pm 23.988 \mathrm{pg} / \mathrm{ml})$, respectively.

Table 4: Odds ratios, $p$ values, and confidence intervals of the LHCGR rs68073206 G/T genotype distribution frequencies in different infertile azoospermic patient groups against the control group

\begin{tabular}{|c|c|c|c|c|}
\hline \multicolumn{5}{|l|}{ LHCGR rs68073206 } \\
\hline Groups versus control & Genotypes and Alleles & $\mathrm{p}$-value & OR & $95 \% \mathrm{Cl}$ \\
\hline \multirow[t]{7}{*}{ Patient I versus control } & Genotype & & & \\
\hline & GG & $0.72 \mathrm{NS}$ & 1.192 & 0.455 to 3.18 \\
\hline & GT & $0.607 \mathrm{NS}$ & 0.7692 & 0.297 to 2.17 \\
\hline & TT & $0.38 \mathrm{NS}$ & 1.954 & 0.447 to 7.81 \\
\hline & Allele & & & \\
\hline & G & 0.937 NS & 0.9702 & 0.4643 to 2.013 \\
\hline & $T$ & & & \\
\hline \multirow[t]{7}{*}{ Patient II versus control } & Genotype & & & \\
\hline & GG & $0.941 \mathrm{NS}$ & 0.965 & 0.383 to 2.44 \\
\hline & GT & $0.260 \mathrm{NS}$ & 0.5401 & 0.198 to 1.49 \\
\hline & TT & $0.7607 \mathrm{NS}$ & 1.954 & 0.447 to 7.81 \\
\hline & Allele & & & \\
\hline & G & 0.7523 NS & 0.8889 & 0.4389 to 1.799 \\
\hline & & \\
\hline
\end{tabular}

Cl: Confidence interval, LHCGR: Luteinizing hormone/Chorionic gonadotropin hormone receptor NS: Non-significant, OR: Odd ratio, Patient I: Azoospermic patients did not receive treatment,

Patient II: Azoospermic patients were receiving treatment.

No more detected statistically significant differences among the means \pm SEM of serum levels of all other studied parameters (inhibin B, LH, FSH, free testosterone E2, progesterone, and prolactin) in infertile azoospermic patient groups or the healthy individuals in control group bearing each of the GG, GT or TT genotypes of the LHCGR gene (rs68073206) polymorphism (Table 5).

\section{Discussion}

The LHCGR is a glycoprotein hormone receptor that belongs to GPCR or the seventransmembrane receptor family [17]. The LHCGR gene that is lying within the 2 p21 chromosomal location in humans involves 11 different exons. The first ten exons within the LHCGR gene are encoded for the portion of the receptor representing the extracellular domains. The remaining exon of the gene is responsible for encoding each of a little part of the extracellular receptor domains, the transmembrane domains, and the cytoplasmic C-terminal domains. It was well known that selective splicing is a commonly reported character of the glycoprotein receptors, including
LHCGR. Numerous variants of the LHCGR splices were established to be originated by alternative splicing and exon skipping. Alterations in the level of the splicing variants expressions, particularly near exon $6 \mathrm{~A}$, result from different rs68073206 LHCGR gene polymorphs, with higher levels of expression in the testes and female granulosa cells [18]. However, the available information regarding the LHCGR variants is minimal because of their association with infertility [19].

In this case-control study that was conducted on the Iraqi population, it has been found that the genotypic prevalence of the LHCGR (rs68073206) polymorphisms had not revealed noticeable differences between the two infertile patients groups (patients with NOA receiving treatment or patient did not receive the treatment) as compared to the healthy fertile normozoospermic control group. The genotypic variations of patients, whether carrying the homozygous GG, heterozygous GT, or homozygous TT genotype, did not reveal a statistically significant difference in the distribution in comparison to the control individuals, so which genotype is associated with higher risk to develop the condition is did not exhibited (Tables 3 and 4).

Liu et al. and colleagues [18] were traced the LHCGR SNP (rs68073206) functional consequences approximate to the exon 6A splicing donor site throughout a study incorporated each of azoospermic, oligoasthenozoospermic, and normozoospermic individuals. The indications that prevailed in their study did not reveal an association of the rs68073206 variants and male factor infertility, to come in consistent with the results revealed by the present study. Another study of 278 patients with maldescended testes estimated the association between the LHCGR gene polymorphismic variants and the disease, and it was concluded that the LHCGR polymorphism (Ser312Asn) in the tenth exon of the LHCGR gene was significantly correlated to spermatogenetic damage owing to its higher predominance amongst the infertile men as compared to that in patients with maldescended testicles [15]. A German case study of Leydig cell hypoplasia type II phenotype with micropenis specified a compound heterozygous fashions inheritance of mutations within the LHCGR gene as a causative agent. The exon 6A localized variants resulting in LHCGR transcripts ratio alterations revealed that these explicit variants ratios

Table 5: Comparison between mean \pm SD of the studied biochemical parameters with different genotypes of rs68073206 SNP of LHCGR gene in the different study groups

\begin{tabular}{|c|c|c|c|c|c|c|c|c|}
\hline Groups & LHCGR rs68073206 Genotyping & Inhibin B (mg/dl) & $\mathrm{FSH} \mathrm{IU/ml}$ & $\mathrm{LH}(\mathrm{mg} / \mathrm{dl})$ & E2 (mg/dl) & Progesterone (mg/dl) & F. Testosterone $(\mathrm{mg} / \mathrm{dl})$ & Prolactin (nglml) \\
\hline \multirow[t]{4}{*}{ Patient I } & GG & $246.445 \pm 224.106$ & $46.758 \pm 26.794$ & $54.434 \pm 23.699$ & $152.371 \pm 30.221$ & $12.513 \pm 9.267$ & $31.149 \pm 5.398$ & $38.063 \pm 7.178$ \\
\hline & GT & $85.969 \pm 71.685$ & $26.937 \pm 11.128$ & $44.271 \pm 16.018$ & $142.176 \pm 40.056$ & $15.245 \pm 6.991$ & $31.550 \pm 5.658$ & $37.909 \pm 9.016$ \\
\hline & TT & $56.420 \pm 23.988$ & $35.697 \pm 19.099$ & $32.615 \pm 8.451$ & $144.711 \pm 27.849$ & $14.746 \pm 9.740$ & $34.445 \pm 3.353$ & $31.33 \pm 3.215$ \\
\hline & p-value & $0.0439^{*}$ & 0.0825 & 0.1782 & 0.7385 & 0.7029 & 0.6258 & 0.3777 \\
\hline \multirow[t]{4}{*}{ Patient II } & GG & $105.770 \pm 73.177$ & $33.793 \pm 17.544$ & $39.356 \pm 8.330$ & $148.687 \pm 43.222$ & $23.615 \pm 6.862$ & $26.552 \pm 8.544$ & $24.821 \pm 11.400$ \\
\hline & GT & $78.896 \pm 19.461$ & $32.133 \pm 6.362$ & $41.250 \pm 11.021$ & $150.467 \pm 65.927$ & $21.385 \pm 6.275$ & $28.484 \pm 3.700$ & $27.201 \pm 16.777$ \\
\hline & TT & $61.543 \pm 32.451$ & $41.378 \pm 23.213$ & $43.987 \pm 8.652$ & $233.392 \pm 198.929$ & $29.576 \pm 5.334$ & $26.051 \pm 3.501$ & $25.524 \pm 4.889$ \\
\hline & $\mathrm{p}$-value & 0.2815 & 0.6135 & 0.6217 & 0.1444 & 0.1249 & 0.7474 & 0.8891 \\
\hline \multirow[t]{4}{*}{ Control } & GG & $418.383 \pm 370.470$ & $19.289 \pm 4.029$ & $32.591 \pm 5.197$ & $123.973 \pm 24.106$ & $17.407 \pm 3.981$ & $32.165 \pm 7.708$ & $19.996 \pm 16.986$ \\
\hline & GT & $693.889 \pm 386.552$ & $24.601 \pm 13.278$ & $32.155 \pm 6.422$ & $130.470 \pm 28.579$ & $16.807 \pm 2.820$ & $36.505 \pm 6.499$ & $19.818 \pm 16.810$ \\
\hline & TT & $673.109 \pm 438.701$ & $29.762 \pm 15.116$ & $33.621 \pm 3.082$ & $121.142 \pm 14.773$ & $15.335 \pm 7.191$ & $28.605 \pm 3.952$ & $14.700 \pm 13.596$ \\
\hline & $\mathrm{p}$-value & 0.1908 & 0.1068 & 0.9037 & 0.7604 & 0.6712 & 0.1524 & 0.8421 \\
\hline
\end{tabular}


were pivotal for the preferable LHCGR action, whether with or without the $6 \mathrm{~A}$ exon. It comprised a preliminary study shedding light on the exon $6 \mathrm{~A}$ imperative character in the act of LHCGR gene supplementary regulator elements and variants that result in shifting transcriptional levels instead of protein level modulations [20]. The contradictory results concerning the relevance of a different LHCGR genotypic variants distribution to the incidence of male factor infertility revealed by these studies can be ascribed to a small sample size along with the diversity of investigated infertility conditions.

The results obtained by the current study as shown in Table 5 also revealed a statistically significant higher hormonal serum level of inhibin $B$ in infertile azoospermic patients who did not receive treatment carrying wild GG genotype compared to that of GT and TT genotypes of LHCGR rs68073206 SNP. Several clinical investigations were asserted that the inhibin B serum levels present a valuable testicular function marker as they prevailed from the positive associations of serum inhibin B levels to the efficiency of testicular function [21], [22]. Another study noticed an exacerbation in serum levels of inhibin B after HCG administration suggesting that testosterone (produced in response to HCG) is required to stimulate inhibin B secretory potential of Sertoli cells or facilitate the stimulatory effects of FSH on Sertoli cells [23] in addition to its stimulatory effect on spermatogenesis, which reflected by inhibin B production; an important index of the spermatogenic status [24].

Furthermore, Liu et al.'s study showed that the LHCGR gene rs68073206 polymorphisms were significantly associated with serum testosterone levels among the GG genotype carriers of normozoospermic subjects [18]. Simoni and co-workers were demonstrated that the polymorphic variants of the LHCGR gene resulted in increased receptor responsiveness in vitro but noticed that these polymorphisms did not distribute differently between patients and controls [15].

In Liu et al. study at the splicing site, the SNP rs68073206 consequences were evidenced to end with alterations in the gene splicing variants related expression ratios. The exon 6A-long (the long transcript) was significantly abundant among the $G / G$ genotype carrier cells, while these transcripts in the $T / T$ and $T / G$ genotypes bearing cells were revealed to be minimally detected or even unnoticeable. Furthermore, the wildtype LHCGR form expression levels were demonstrated to come with an enhanced G/G genotype tendency. Moreover, an augmented wild-type LHCGR levels give rise to increased long transcripts expressions, rendering the receptor highly susceptible to stimulations by their ligands [18]. The LHCGR variant was also found to results in an observed functional change of the LHCGR 291Ser candidate allele, the state that can be attributed to increased LHCGR sensitivity [25]. Other publications covering the genetic causes of male factor infertility were stated the association of LHCGR gene variants with low or diminished sperm counts [26], [27]. Alternatively, link the state of gonadotrophin-resistant testes and consequently male infertility to LHCGR receptor polymorphisms [28].

However, other researchers have speculated the weakness of the LHCGR SNPs contributions to a peculiar phenotype, added to the lack of a pronounced (within this gene) phenotypic markers and the absence of clear male reproductive functions related impacts [13]. Others were further proposed that various polymorphisms in LHCGR are still silent, with an excluded significance in their functional consequences [14]. Overall, it can be suggested that this enhanced serum inhibin B levels in a selected genotype carrier (GG genotype) of the studied LHCGR gene variant can be attributed to an enhanced receptor sensitivity to LH levels in Leydig cells as compared to other genotypes carriers.

\section{Conclusion}

The LHCGR gene rs68073206 polymorphisms in our populationpresented with non-obstructive azoospermia; are suggested to have atuning potential in gonadotropin receptor sensitivity and variableinfertility treatment outcome. Genotypic prevalence of LHCGR geners68073206 polymorphism in infertile men with NOA didn't differentlydistributed from that of fertile normozoospermic individuals.

\section{References}

1. Mascarenhas MN, Flaxman SR, Boerma T, Vanderpoel $\mathrm{S}$, Stevens GA. National, regional, and global trends in infertility prevalence since 1990: A systematic analysis of 277 health surveys. PLoS Med. 2012;9:e1001356. https://doi.org/10.1371/ journal.pmed.1001356

PMid:23271957

2. Kumar N, Singh AK. Trends of male factor infertility, an importan cause of infertility: A review of literature. J Hum Reprod Sci. 2015;8(4):191-6. https://doi.org/10.4103/0974-1208.170370 PMid:26752853

3. World Health Organization. WHO Laboratory Manual for The Examination and processing of Human Semen. $5^{\text {th }}$ ed. Geneva: World Health Organization; 2010. p. 10-56.

4. Chow AK, Levine LA. Testicular sperm aspiration in men with presumed non-obstructive azoospermia: Analysis of FSH level as a predictor of successful sperm retrieval. J Genital Surg 2019;1:1-8. https://doi.org/10.21608/jgs.2017.4795

5. Chen X, Ma Y, Zou S, Wang S, Qiu J, Xiao Q, et al. Comparison and outcomes of non-obstructive azoospermia patients with different etiology undergoing MicroTESE and ICSI treatments. Transl Androl Urol. 2019;8(4):366-373. https://doi.org/10.21037/ 


\section{tau.2019.04.08}

PMid:31555560

6. Yumusak OH, Cinar M, Kahyaoğlu S, Buyuk GN, Oksuzoglu A Tasci Y. Can testicular size be a predictive factor for successful sperm retrieval in patients with non-obstructive azoospermia? Reprod Med Endocrinol Infertil. 2019;25:1-5. https://doi. org/10.21613/gorm.2018.890

7. Karamazak S, Kızılay F, Bahçeci T, Semerci B. Do body mass index, hormone profile and testicular volume effect sperm retrieval rates of microsurgical sperm extraction in the patients with non-obstructive azoospermia? Turk J Urol. 2018;44(3):202-7. https://doi.org/10.5152/tud.2017.80000 PMid:29733793

8. Vezzoli V, Duminuco P, Vottero A, Kleinau G, Schülein R, Minari $\mathrm{R}$, et al. A new variant in signal peptide of the human luteinizing hormone receptor (LHCGR) affects receptor biogenesis causing leydig cell hypoplasia. Hum Mol Genet. 2015;24(21):6003-12. https://doi.org/10.1093/hmg/ddv313 PMid:26246498

9. Riccetti L, De Pascali F, Gilioli L, Potì F, Giva LB, Marino M, et al Human LH and hCG stimulate differently the early signalling pathways but result in equal testosterone synthesis in mouse Leydig cells in vitro. Reprod Biol Endocrinol. 2017;15(1):2. https://doi.org/10.1186/s12958-016-0224-3 PMid:28056997

10. Herati AS, Kohn TP, Kassiri B. New frontiers in fertility preservation: A hypothesis on fertility optimization in men with hypergonadotrophic hypogonadism. Transl Androl Urol. 2020;9(2):S171-7. https://doi.org/10.21037/tau.2019.12.39 PMid:32257857

11. Troppmann B, Kleinau G, Krause G, Gromoll J. Structural and functional plasticity of the luteinizing hormone/ choriogonadotrophinreceptor. Hum Reprod Update. 2013;19:583-602. https://doi.org/10.1093/humupd/dmt023

12. Krause G, Kreuchwig A, Kleinau G. Extended and structurally supported insights into extracellular hormone binding, signal transduction and organization of the thyrotropin receptor PLoS One. 2012;7(12):1-11. https://doi.org/10.1371/journal. pone.0052920

PMid:23300822

13. Casarini L, Huhtaniemi I, Simoni M, Rivero-Müller A Gonadotrophin receptors. In: Endocrinology of the Testis and Male Reproduction. Switzerland: Springer; 2017. p. 1-46: https://doi.org/10.1007/978-3-319-44441-3_4

14. Huhtaniemi I, Rivero-Müller A. Mutations and polymorphisms, and their functional consequences, in gonadotropin and gonadotropin receptor genes. Ovary. 2019;2019:127-48. https:// doi.org/10.1016/b978-0-12-813209-8.00008-x

15. Simoni M, Tuttelmann F, Michel C, Bockenfeld Y, Nieschlag E, Gromoll J. Polymorphisms of the luteinizing hormone/ chorionic gonadotropin receptor gene: Association with maldescended testes and male infertility. Pharmacogenet Genomics. 2008:18(3):193-200. https://doi.org/10.1097/ fpc.0b013e3282f4e98c PMid: 18300940

16. World Medical Association. World medical association declaration of Helsinki: Ethical principles for medical research involving human subjects. JAMA. 2013;310(20):2191-4. https:// doi.org/10.1001/jama.2013.281053

PMid:24141714

17. Althumairy D, Zhang $X$, Baez N, Barisas G, Roess DA, Bousfield GR, et al. Glycoprotein G-protein coupled receptors in disease: Luteinizing hormone receptors and follicle stimulating hormone receptors. Diseases. 2020;8(3):35. https://doi. org/10.3390/diseases 8030035

\section{PMid:32942611}

18. Liu W, Han B, Zhu W, Cheng T, Fan M, Wu J, et al. Polymorphism in the alternative donor site of the cryptic exon of LHCGR: Functional consequences and associations with testosterone level. Sci Rep. 2017;7:45699. https://doi.org/10.1038/srep45699 PMid:28367994

19. Lindgren I, Bååth $M$, Uvebrant K, Dejmek A, Kjaer L, Henic E, et al. Lundberg Giwercman, Combined assessment of polymorphisms in the LHCGR and FSHR genes predict chance of pregnancy after in vitro fertilization. Hum Reprod. 2016;31(3):672-83. https://doi.org/10.1093/humrep/dev342 PMid:26769719

20. Kossack N, Troppmann B, Richter-Unruh A, Kleinau G, Gromoll J. Aberrant transcription of the LHCGR gene caused by a mutation in exon 6A leads to Leydig cell hypoplasia type II. Mol Cell Endocrinol. 2013;366(1):59-67. https://doi.org/10.1016/j. mce.2012.11.018 PMid:23232123

21. Braga LH, Lorenzo AJ. The changing elaboration of inhibin b in patients with unilateral testicular maldescent vs vanished testis. J Urol. 2015;193(5):1465-6. https://doi.org/10.1016/j. juro.2015.02.076

PMid:25700564

22. Huang X, Bai Q, Yan LY, Zhang QF, Geng L, Qiao J. Combination of serum inhibin $B$ and follicle-stimulating hormone levels can not improve the diagnostic accuracy on testicular sperm extraction outcomes in Chinese non-obstructive azoospermic men. Chin Med J (Engl). 2012;125(16):2885-9. PMid:22932085

23. Giagulli VA, Carbone D. Hormonal control of inhibin B in men. J Endocrinol Investig. 2006;29(8):706-13. https://doi. org/10.1007/bf03344180

PMid:17033259

24. Petrozzi A, Pallotti F, Pelloni M, Anzuini A, Radicioni AF, Lenzi A, et al. Inhibin B: Are modified ranges needed for orchiectomised testicular cancer patients? Asian J Androl. 2019;21(4):332-6. https://doi.org/10.4103/aja.aja_93_18

PMid:30531061

25. Piersma D, Verhoef-Post M, Look MP, Uitterlinden AG, Pols HA Berns EM, etal. Polymorphic variations in exon 10 of the luteinizing hormone receptor: Functional consequences and associations with breast cancer. Mol Cell Endocrinol. 2007;276(1-2):63-70. https://doi.org/10.1016/j.mce.2007.06.007 PMid:17709176

26. Oud MS, Volozonoka L, Smits RM. A systematic review and standardized clinical validity assessment of male infertility genes. Hum Reprod. 2019;34(5):932-41. https://doi. org/10.1101/425553 PMid:30865283

27. Salas-Huetos A, Aston KI. Defining new genetic etiologies of male infertility: Progress and future prospects. Transl Androl Urol. 2021;10(3):1486-98. https://doi.org/10.21037/ tau.2020.03.43 PMid:33850783

28. Acién $P$, Maribel A. Disorders of sex development: Classification, review, and impact on fertility. J Clin Med. 2020;9(11):3555. https://doi.org/10.3390/jcm9113555

PMid:33158283 